Research Paper

\title{
Local surgical excision versus endoscopic resection for rectal carcinoid: A meta-analysis.
}

\author{
Qiaoqi Sui*, Junzhong Lin*, Jianhong Peng, Yujie Zhao, Yuxiang Deng, Zhizhong Pan ${ }^{凶}$ \\ Department of Colorectal Surgery, Sun Yat-sen University Cancer Center; State Key Laboratory of Oncology in South China; Collaborative Innovation Center for \\ Cancer Medicine Guangzhou \\ ${ }^{*}$ Qiaoqi Sui and Junzhong Lin contribute equally to this study \\ $\triangle$ Corresponding author: Zhizhong Pan, Department of Colorectal Surgery, Sun Yat-sen University Cancer Center; State Key Laboratory of Oncology in South \\ China; Collaborative Innovation Center for Cancer Medicine Guangzhou, 510060, P.R. China. Tel: +86-13719388166; Fax: +86-20-87343637; E-mail: \\ callen@medmail.com.cn \\ (C) Ivyspring International Publisher. This is an open access article distributed under the terms of the Creative Commons Attribution (CC BY-NC) license \\ (https://creativecommons.org/licenses/by-nc/4.0/). See http://ivyspring.com/terms for full terms and conditions.
}

Received: 2017.06.14; Accepted: 2017.09.30; Published: 2017.10.23

\begin{abstract}
Purpose: To date, there is not enough evidence concerning the optimal treatment strategy for early rectal carcinoids, we conducted a meta-analysis in order to determine the feasible local treatment for these selected patients.

Methods: We searched the studies from the PubMed, Cochrane database, Medline, Ovid, SpringerLink, PMC and Embase between January 2007 and April 2017. Studies of local surgical excision compared with endoscopic resection for rectal carcinoids less than $20 \mathrm{~mm}$ without adverse features were included. Data were analyzed by using Stata SE 12.0.

Results: Seven studies were included in this meta-analysis, with a total of 1056 patients. The data showed that local surgical excision was associated with higher complete resection rate than that of endoscopic resection (OR 5.837, $95 \% \mathrm{Cl} 2.048$ to $16.632, \mathrm{P}=0.001$ ) but consuming longer procedural time (SMD $1.757,95 \% \mathrm{Cl} 1.263$ to $2.251, \mathrm{P}=0.000$ ). Additionally, incidences of recurrence and en bloc resection rate were comparable between two kinds of resections. The difference of post-operative complications remained unclear.

Conclusions: For rectal carcinoids sized $20 \mathrm{~mm}$ or smaller without adverse features, endoscopic resection might be an efficient treatment, which achieved a comparable oncological safety as local surgical excision.
\end{abstract}

Key words: rectal carcinoids sized $20 \mathrm{~mm}$ or smaller without adverse features; local surgical excision; endoscopic resection; complete resection; recurrence

\section{Introduction}

Carcinoid tumors, derived from neuroendocrine cells compartments, mostly arise along the intestine, among which rectum was found to be the third most frequent predilection site[1, 2]. Currently, rectal carcinoids with adverse features for metastasis including diameters larger than $20 \mathrm{~mm}$, invading muscularis propria, lymphovascular invasion or positive regional lymph node, are suggested to be removed by radical surgery, while tumors in diameters $10 \mathrm{~mm}$ or less are supposed to be treated by local resection[3-5]. As for the carcinoids sized between $10 \mathrm{~mm}$ to $20 \mathrm{~mm}$, the management remains controversial. Previous studies reported that rectal carcinoids sized 10 to $20 \mathrm{~mm}$ without adverse features can benefit from locally resection irrespective of whether endoscopic or surgical treatment [6-8].

Endoscopic resection, including polypectomy, endoscopic mucosal resection (EMR) and endoscopic submucosal dissection (ESD), is widely used for the local management for rectal carcinoids due to high efficiency and safety[9-11]. Meanwhile, transanal excision (TAE) as well as transanal endoscopic 
microsurgery (TEM), the significant roles of local surgical treatment, ensure high efficiency for complete resection as well as low rate of complications and recurrence for rectal carcinoids[8, 12].

Nevertheless, it remains unclear whether endoscopic resection or local surgical excision can provide better postoperative outcomes for the selected patients. Besides, there is no guideline or consensus concerning the optimal local treatment strategy for carcinoids removal. To answer this question, the current meta-analysis aimed to compared the efficiency and safety between local surgical excision and endoscopic resection and determine the optimal strategy for rectal carcinoids sized $20 \mathrm{~mm}$ or smaller without adverse features.

\section{Materials and Methods}

\section{Literature search}

The PubMed, Cochrane database, Medline, Ovid, SpringerLink, PMC and Embase were searched from January 2007 to April 2017. Search terms included "rectal carcinoids", "neuroendocrine tumors", "rectum", "endoscopic resection", "transanal excision", "surgical excision". Bibliographies of relevant reviews, retrieved articles and meta-analysis were identified for sources. All the abstracts, studies and citations were totally reviewed.

\section{Inclusion criteria}

Studies meeting following criteria were included: (1) Including rectal carcinoids sized $20 \mathrm{~mm}$ or smaller without adverse features (2) Including local surgical excision and endoscopic resection (3) At least one outcome available directly or through calculation (4) Published in English. We excluded reviews, pooled-analysis, case reports, position papers as well as editorials and those outcomes were not reported or unable to be calculated from results.

\section{Data extraction}

Two researchers assessed titles and abstracts of studies identified by the search strategies. The full publications of all possibly relevant abstracts were obtained and formally assessed for inclusion. Two reviewers extracted the following information independently from each study: first author, year of publication, study design, treatments, population, size of tumors, follow-up, outcomes including procedural time, cases of perforation and bleeding, en bloc resection rate, complete resection rate and recurrence.

We used the Newcastle-Ottawa Scale(NOS) to assess the quality of the non-randomized studies included.

\section{Statistical analysis}

We carried out statistical analysis with STATA SE 12.0 software integration (StataCorp, Houston, Texas, USA). The odds ratio (OR), rate difference (RD), standardized mean difference (SMD) and 95\% confident interval (CI) were calculated for studies included. Statistical heterogeneity between studies was assessed by the chi-squared test with a $P$ value, of which 0.10 was set to be significant. The quantity of heterogeneity measured using the $I^{2}$ statistic. $I^{2}$ was put between $0 \%$ and $100 \%$, equal to zero when no heterogeneity. A fix effects model was used for pooling of data when statistical heterogeneity was not present, otherwise a randomized effects model was used. We measured the publication bias with Begg's test and Egger's test.

\section{Results}

\section{Search results of studies}

Figure 1 shows the procedure of selection for study inclusion. 290 records were identified by the primary computerized literature search. After screening the titles and abstracts, we excluded 277 records not concerning. The full texts of the retrieved 13 manuscripts were read thoroughly, among which 6 studies were excluded for unclear report of their characteristics of patients or their outcomes. Finally, we included 7 studies in the meta-analysis, with a total of 1056 patients[13-19]. Among these patients, 126 were treated with local surgical excision and 930 with endoscopic resection. It should be noted that in the study of Kasuga et al, 22 patients took radical surgery after endoscopic treatment due to positive resection margin[14]. The characteristics of the 7 studies included in this paper were shown in Table. 1 and the results of NOS were shown in Table. 2. The outcomes were shown in Table. 3. Tumors were found to be sized $20 \mathrm{~mm}$ or less, without muscularis propria or lymphovascular invasion and regional lymph node metastasis.

\section{Procedural time}

Two studies reported the procedural time for their treatments. As for the endoscopic resection, the study conducted by Jeon reported the mean time for both ESD and EMR, while Yan reported the mean procedural time for ESD[13, 19]. Therefore, we extracted mean procedural time for ESD. The mean time for local surgical excision was longer than that for ESD significantly, with overall pooled SMD of the mean procedural times for local surgical excision vs ESD 1.757 (95\% CI 1.263 to 2.251, P=0.000) (Fig.2). 


\section{Operative complication}

Only 2 studies reported the rate of complication including bleeding and perforation, which is rare and unsuitable for meta-analysis. The study done by Jeon et al indicates that 16 patients suffered from bleeding, 5 after EMR and 11 after ESD. Apart from that, there was no bleeding or perforations reported.

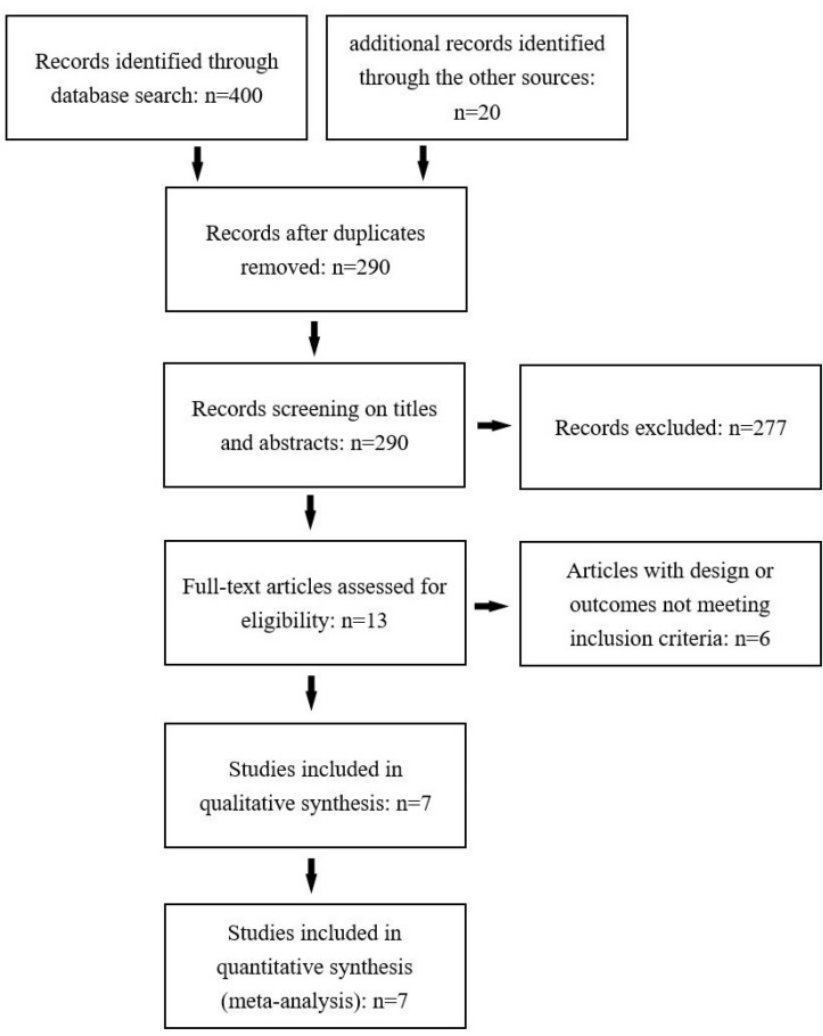

Fig. 1. Flow chart of the study selection process and exclusion criteria.

\section{En bloc resection}

An en bloc resection was defined as no residual tumors under endoscope after resection. Three studies reported this outcome. The overall RD was 0.054 (95\% CI -0.005 to $0.114, \mathrm{P}=0.073$ ) (Fig.3). This meta-analysis shows that local surgical excision achieves a similar rate of en bloc resection as endoscopic resection.

\section{Complete resection}

A complete resection was defined as a negative margin on histopathological examination after resection. The forest plot in Figure 3 summarizes the results of 5 studies, with an overall pooled OR 5.837 (95\% CI 2.048 to $16.632, \mathrm{P}=0.001$ ) (Fig.4). The analysis indicates that local surgical excision is more capable of complete resection than endoscopic resection. There is no present significant publication bias according to Begg's test $(\mathrm{P}=0.806)$ as well as the Egger's test $(\mathrm{P}=0.609)$.

Table 1. Characteristics of studies included.

\begin{tabular}{|c|c|c|c|c|c|c|}
\hline Study & Year & Design & Treatment & $\mathrm{N}$ & 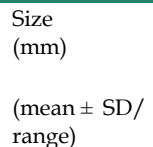 & $\begin{array}{l}\begin{array}{l}\text { Mean } \\
\text { follow-up } \\
\text { (month) }\end{array} \\
( \pm \mathrm{SD} / \\
\text { range) }\end{array}$ \\
\hline $\begin{array}{l}\text { Jeon et } \\
\text { al. }\end{array}$ & 2014 & Retro & $\begin{array}{l}\text { EMR/ESD/ } \\
\text { TEM }\end{array}$ & 66 & $\leq 20$ & $\begin{array}{l}\text { EMR } \\
20.4 \pm 14.5 \\
\text { ESD } \\
29.1 \pm 12.3 \\
\text { TEM } \\
13.2 \pm 6.1\end{array}$ \\
\hline Kimetal. & 2013 & Retro & EMR/TAE & 94 & $\leq 20$ & $32.8(0.3-125.3)$ \\
\hline $\begin{array}{l}\text { Park et } \\
\text { al. }\end{array}$ & 2009 & Retro & ER/TAE & 318 & $7.2 \pm 3.4$ & $\begin{array}{l}\text { ER } \\
48(25-159) \\
\text { TAE } \\
56(28-164)\end{array}$ \\
\hline Yanetal. & 2016 & Retro & ESD/TALE & 54 & $\begin{array}{l}\text { ESD } 8 \pm 2 \\
\text { TALE } 11 \pm 5\end{array}$ & NA \\
\hline Son et al. & 2013 & Retro & $\begin{array}{l}\text { Polypectomy/ } \\
\text { Strip biopsy/ } \\
\text { EMR-C/ESD/ } \\
\text { TEM/TAE }\end{array}$ & 166 & $\begin{array}{l}5.51 \pm 2.43 \\
(2-18)\end{array}$ & $33.26 \pm 24.02$ \\
\hline Kimet al. & 2014 & Retro & $\begin{array}{l}\text { Polypectomy/ } \\
\text { ESD/EMR/TAE }\end{array}$ & 171 & $\leq 20$ & $\begin{array}{l}\text { ER } \\
28(13-119) \\
\text { TAE } \\
\text { NA }\end{array}$ \\
\hline $\begin{array}{l}\text { Kasuga } \\
\text { et al. }\end{array}$ & 2012 & Retro & ER/LR & 167 & $\leq 20$ & $44.2 \pm 35.8$ \\
\hline
\end{tabular}

Table 2. Newcastle-Ottawa Scale of studies included.

\begin{tabular}{|c|c|c|c|c|c|c|c|c|c|}
\hline \multirow[b]{2}{*}{ Study } & \multicolumn{4}{|c|}{ Selection } & \multirow{2}{*}{$\frac{\text { Comparability }}{1}$} & \multicolumn{3}{|c|}{$\begin{array}{l}\text { Outcome } \\
\text { assessment }\end{array}$} & \multirow[b]{2}{*}{ Score } \\
\hline & 1 & 2 & 3 & 4 & & 1 & 2 & 3 & \\
\hline Jeon et al. & $\star$ & & $\star$ & $\star$ & $\star \star$ & $\star$ & $\star$ & & 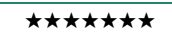 \\
\hline Kim et al. & $\star$ & & $\star$ & $\star$ & $\star$ & $\star$ & $\star$ & & $\star \star \star \star \star \star$ \\
\hline Park et al. & $\star$ & & $\star$ & $\star$ & $\star$ & $\star$ & & $\star$ & 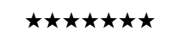 \\
\hline Yan et al. & $\star$ & & $\star$ & $\star$ & $\star \star$ & $\star$ & $\star$ & $\star$ & 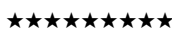 \\
\hline Son et al. & $\star$ & & $\star$ & $\star$ & $\star$ & $\star$ & $\star$ & $\star$ & 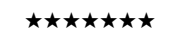 \\
\hline Kim et al. & $\star$ & & $\star$ & $\star$ & $\star$ & $\star$ & $\star$ & $\star$ & 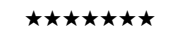 \\
\hline $\begin{array}{l}\text { Kasuga } \\
\text { et al. }\end{array}$ & $\star$ & & $\star$ & $\star$ & $\star$ & $\star$ & $\star$ & $\star$ & 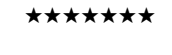 \\
\hline
\end{tabular}

\section{Recurrence}

Overall, 1 patient treated with surgical excision and 5 patients with endoscopic resection experienced either local or systematic recurrence. Despite that, the pooled RD of recurrence rate is $-0.002(95 \% \mathrm{CI}-0.044$ to $0.041 \mathrm{P}=0.936$ ) (Fig.5.). There is no significant difference of recurrence rate between tumors treated with surgical excision and endoscopic resection.

\section{Discussion}

Our study shows that local surgical excision, compared to endoscopic resection, achieves a higher 
rate of complete resection but is more time-consuming for rectal carcinoids. Moreover, two kinds of resections share similar en bloc resection rate as well as recurrence rate. The difference of operative complications remains uncertain.

Endoscopic resection, removing tumors superficial, enables en bloc resection for rectal carcinoids but sometimes unable to ensure pathological complete resection. Park[20] and Yang[10] reported that both EMR with a cap(EMR-C) and ESD provided $100 \%$ en bloc resection for rectal carcinoids, but the highest complete resection rate among endoscopic resections reached $94.1 \%$ and $92.3 \%$. In our study, the complete resection rates of endoscopic resections were ranged $57.4 \%$ to $96.8 \%$. It was indicated that endoscopic resection cannot always achieve tumors located on the submucosal level[10, 20, 21]. Kumar[8] and Chen[22], on the other hand, reported that TEM achieved 100\% negative margin for typical rectal carcinoids smaller than $20 \mathrm{~mm}$, pointing out that TEM is capable for full-thickness excision for rectal carcinoids smaller than $20 \mathrm{~mm}$ and allows a total removal of submucosal layer. Additionally, a meta-analysis done by Arezzo et al in 2013 indicates that TEM achieves higher rates of complete resection than ESD for large noninvasive rectal tumors [23]. The result of our meta-analysis also proves that local surgical excision obtains a significantly higher complete resection rate than endoscopic resection, supporting the statements that local surgical excision is more likely to achieve complete resection for rectal carcinoids in diameters $20 \mathrm{~mm}$ or less.

It was advocated that after excision for rectal carcinoids, positive margins could lead to recurrence and are supposed to be managed by additional surgery [21, 24], while according to our metaanalysis, carcinoids receiving proper follow-up, shared a similar recurrence rate despite different complete resection rate after two kinds of resections. Kaneko [25] and Kim [26] also reported 11 and 54 patients with rectal carcinoids sized smaller than $10 \mathrm{~mm}$ who did not demonstrated recurrence with positive resection margins. Besides, a meta-analysis carried out by Zhong proved that in spite of a significant difference of complete resection rates, recurrence rates of rectal carcinoids smaller than $16 \mathrm{~mm}$ in diameters treated with ESD and EMR are low and similar[27]. Kim indicated

Fig. 3. Forest plot showing the rate of en bloc resection of local surgical excision compared with endoscopic resection. 
that such phenomenon may due to the low malignant potential of small rectal carcinoids included[26]. More significantly, Chen[28], analyzing 6 cases of metastasis among 239 patients receiving ESD, found that lymphovascular invasion, one of the adverse features of metastasis, also serves as a risk factor of systematic recurrence. Low malignancy and lack of adverse features could make an explanation for our findings. Our results show that both local surgical excision and endoscopic resection are safe and appropriate for rectal carcinoids sized smaller than $20 \mathrm{~mm}$ without adverse feature, and positive resection margins may not be a risk factor for recurrence.

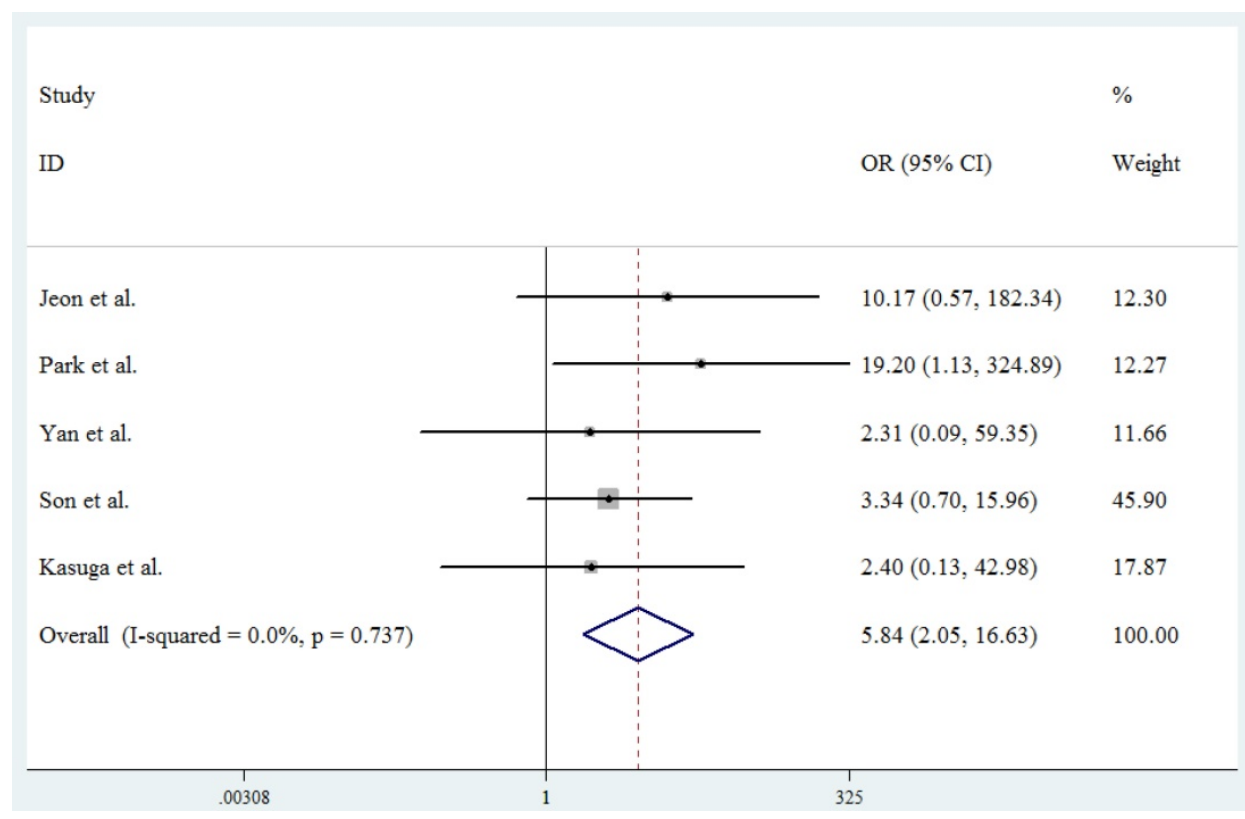

Fig. 4. Forest plot showing the complete resection rate of local surgical excision compared with endoscopic resection.

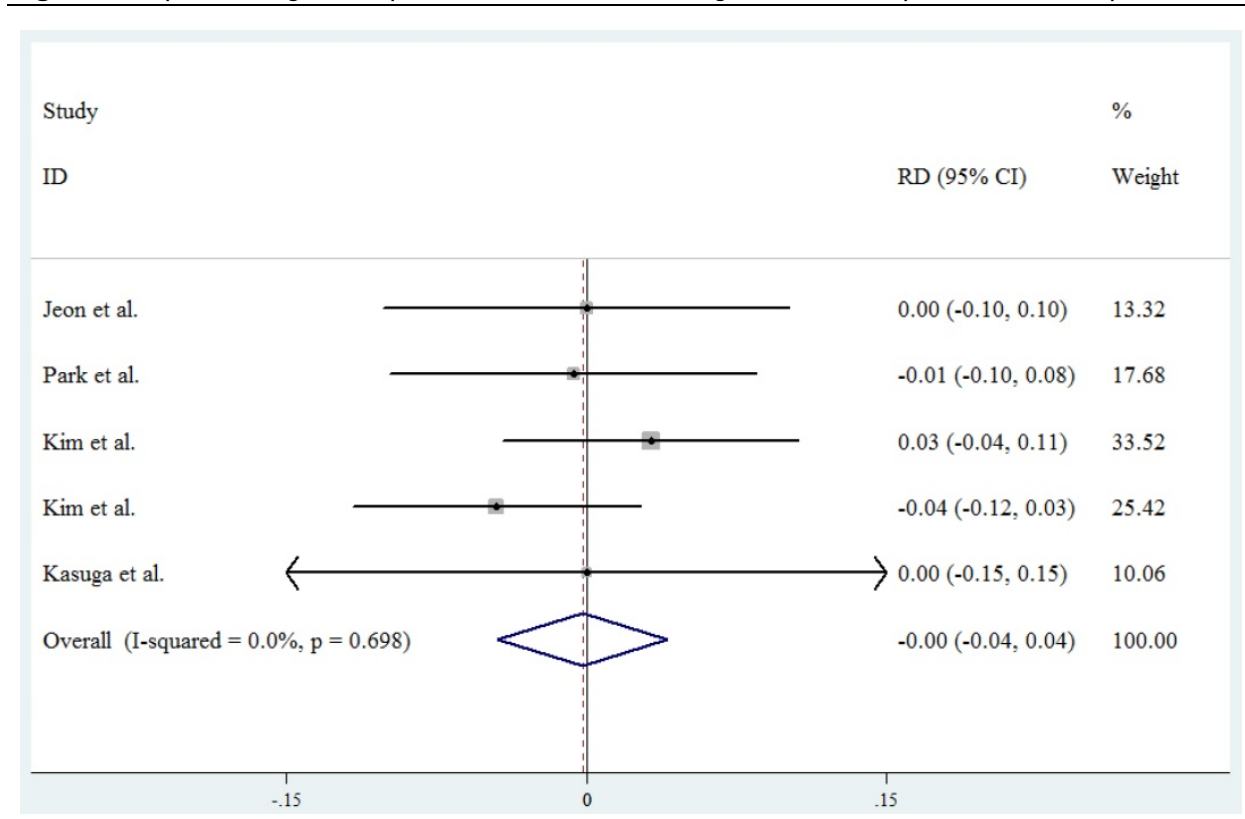

Fig. 5. Forest plot showing the recurrence rate of local surgical excision compared with endoscopic resection.
Although we failed to make comparison of complications through meta-analysis, the study by Jeon[13] still reported 16 bleeding after endoscopic resection, significantly different compared to 0 among patients receiving TEM. However, reported by Park[20] and Yang[10], the rate of bleeding is low after endoscopic resection, and no perforations were found. What's more, Lee observed only 2 bleedings and 1 perforation among 46 patients treated with ESD and 1 bleeding among 28 patients receiving EMR[29]. The reason might be the difference of performance and experience of surgeons. As for local surgical excision, there were neither bleedings nor perforations found among studies included. Kumar [12] found that bleedings after TEM are rare, only 4 among 325 patients, and proved the association between large-size and intraoperative bleeding as well. According to that, carcinoid tumors smaller than $20 \mathrm{~mm}$ may be less likely to develop bleedings or perforations during or after local surgery. However, surgical excision could trigger other complications rarely found among endoscopic resection cases, like urinary retention and anus ache. In our study, Yan[19] reported 5 urinary retentions and 16 anus aches caused by spinal anesthesia and operative anal. Kumar, meanwhile, found 19 urinary retentions after TEM, which may require inpatient hospitalization [12]. Complications brought by endoscopic resection could be easily managed through interventions, while those by local surgical excision were severe. More comparative studies of complications are required to further assess the relative complications of endoscopic resections and local surgical excision. 
Table 3. Outcomes of local surgical excision vs endoscopic resection.

\begin{tabular}{|c|c|c|c|c|c|c|}
\hline Study & $\begin{array}{l}\text { Procedural time } \\
(\text { Mean } \pm S D, \text { min) }\end{array}$ & Perforation & Bleeding & En bloc & CR & Recurrence \\
\hline $\begin{array}{l}\text { Jeon et } \\
\text { al. }\end{array}$ & $40.7 \pm 14.2 / 18 \pm 13.2$ & $0 / 0$ & $0 / 16$ & $13 / 52$ & $13 / 38$ & $0 / 0$ \\
\hline $\begin{array}{l}\text { Park et } \\
\text { al. }\end{array}$ & NA & NA & NA & $14 / 268$ & $\begin{array}{l}14 / 18 \\
3\end{array}$ & $0 / 2$ \\
\hline $\begin{array}{l}\text { Yanet } \\
\text { al. }\end{array}$ & $40 \pm 22.7 / 12.2 \pm 5.3$ & $0 / 0$ & $0 / 0$ & $23 / 30$ & $23 / 30$ & NA \\
\hline $\begin{array}{l}\text { Kim et } \\
\text { al. }\end{array}$ & NA & NA & NA & NA & NA & $1 / 0$ \\
\hline $\begin{array}{l}\text { Son et } \\
\text { al. }\end{array}$ & NA & NA & NA & NA & $9 / 89$ & NA \\
\hline $\begin{array}{l}\text { Kim et } \\
\text { al. }\end{array}$ & NA & NA & NA & NA & NA & $0 / 3$ \\
\hline $\begin{array}{l}\text { Kasuga } \\
\text { et al. }\end{array}$ & NA & NA & NA & NA & $8 / 159$ & $0 / 0$ \\
\hline
\end{tabular}

En bloc: en bloc resection

CR: complete resection.

NA: not available.

Our analysis has certain limitations. Firstly, studies included are all retrospective. Without RCT, the bias could affect the results. Secondly, we lack reports of procedural time, which may lead to selection bias. Thirdly, we cannot analysis the outcomes of tumors in diameters 10 to $20 \mathrm{~mm}$ and less than $10 \mathrm{~mm}$ by subgroups due to unclear reports. Fourthly, the grading of carcinoids in our study was uncertain.

In conclusion, for rectal carcinoids sized $20 \mathrm{~mm}$ or smaller without adverse features, endoscopic resection might be served as an efficient treatment, which achieved a comparable oncological safety as local surgical excision.

\section{Abbreviations}

EMR: endoscopic mucosal resection; ESD: endoscopic submucosal dissection; TAE: transanal excision; TEM: transanal endoscopic microsurgery; TALE: transanal local excision; ER: endoscopic resection; LR: local resection; CR: complete resection; NOS: Newcastle-Ottawa Scale; OR: odds ratio; RD: rate difference; SMD: standardized mean difference; CI: confident interval; EMR-C: EMR with a cap; Retro: retrospective; Fig.: figure.

\section{Competing Interests}

The authors have declared that no competing interest exists.

\section{References}

1. Modlin IM, Lye KD, Kidd M. A 5-decade analysis of 13,715 carcinoid tumors. Cancer. 2003; 97: 934-59.

2. Modlin IM, Kidd M, Latich I, Zikusoka MN, Shapiro MD. Current Status of Gastrointestinal Carcinoids. Gastroenterology. 2005; 128: 1717-51.

3. Harada H, Suehiro S, Murakami D, Nakahara R, Shimizu T, Katsuyama Y, et al. Endoscopic submucosal dissection for small submucosal tumors of the rectum compared with endoscopic submucosal resection with a ligation device. World J Gastrointest Endosc. 2017; 9: 70-6.

4. Wang M, Peng J, Yang W, Chen W, Mo S, Cai S. Prognostic analysis for carcinoid tumours of the rectum: a single institutional analysis of 106 patients. Colorectal Dis. 2011; 13: 150-3.
5. Yoon SN, Yu CS, Shin US, Kim CW, Lim SB, Kim JC. Clinicopathological characteristics of rectal carcinoids. Int J Colorectal Dis. 2010; 25: 1087-92.

6. McConnell YJ. Surgical management of rectal carcinoids: trends and outcomes from the Surveillance, Epidemiology, and End Results database (1988 to 2012). Am J Surg. 2016; 211: 877-85.

7. Shigeta K, Okabayashi K, Hasegawa H, Ishii Y, Ochiai H, Tsuruta M, et al. Long-term outcome of patients with locally resected high- and low-risk rectal carcinoid tumors. J Gastrointest Surg. 2014; 18: 768-73.

8. Kumar AS, Sidani SM, Kolli K, Stahl TJ, Ayscue JM, Fitzgerald JF, et al. Transanal endoscopic microsurgery for rectal carcinoids: the largest reported United States experience. Colorectal Dis. 2012; 14: 562-6.

9. He L, Deng T, Luo H. Efficacy and safety of endoscopic resection therapies for rectal carcinoid tumors: a meta-analysis. Yonsei Med J. 2015; 56: 72-81.

10. Yang DH, Park Y, Park SH, Kim KJ, Ye BD, Byeon JS, et al. Cap-assisted EMR for rectal neuroendocrine tumors: comparisons with conventional EMR and endoscopic submucosal dissection (with videos). Gastrointest Endosc. 2016; 83: 1015-22; quiz 23- e6.

11. McDermott FD, Heeney A, Courtney D, Mohan H, Winter D. Rectal carcinoids: a systematic review. Surg Endosc. 2014; 28: 2020-6.

12. Kumar AS, Coralic J, Kelleher DC, Sidani S, Kolli K, Smith LE. Complications of transanal endoscopic microsurgery are rare and minor: a single institution's analysis and comparison to existing data. Dis Colon Rectum. 2013; 56: 295-300.

13. Jeon JH, Cheung DY, Lee SJ, Kim HJ, Kim HK, Cho HJ, et al. Endoscopic resection yields reliable outcomes for small rectal neuroendocrine tumors. Dig Endosc. 2014; 26: 556-63.

14. Kasuga A, Chino A, Uragami N, Kishihara T, Igarashi M, Fujita R, et al. Treatment strategy for rectal carcinoids: a clinicopathological analysis of 229 cases at a single cancer institution. J Gastroenterol Hepatol. 2012; 27: 1801-7.

15. Kim DH, Lee JH, Cha YJ, Park SJ, Cheon JH, Kim TI, et al. Surveillance strategy for rectal neuroendocrine tumors according to recurrence risk stratification. Dig Dis Sci. 2014; 59: 850-6.

16. Kim MS, Hur H, Min BS, Baik SH, Lee KY, Kim NK. Clinical outcomes for rectal carcinoid tumors according to a new (AJCC 7th edition) TNM staging system: a single institutional analysis of 122 patients. J Surg Oncol. 2013; 107: 835-41.

17. Park $\mathrm{CH}$, Cheon JH, Kim JO, Shin JE, Jang BI, Shin SJ, et al. Criteria for decision making after endoscopic resection of well-differentiated rectal carcinoids with regard to potential lymphatic spread. Endoscopy. 2011; 43: $790-5$

18. Son HJ, Sohn DK, Hong CW, Han KS, Kim BC, Park JW, et al. Factors associated with complete local excision of small rectal carcinoid tumor. Int J Colorectal Dis. 2013; 28: 57-61.

19. Yan FH, Lou Z, Hu SJ, Xu XD, Wang H, Wang HT, et al. Endoscopic submucosal dissection versus transanal local excision for rectal carcinoid: a comparative study. World J Surg Oncol. 2016; 14: 162.

20. Park SB, Kim HW, Kang DH, Choi CW, Kim SJ, Nam HS. Advantage of endoscopic mucosal resection with a cap for rectal neuroendocrine tumors. World J Gastroenterol. 2015; 21: 9387-93.

21. Yangong $\mathrm{H}$, Shi $\mathrm{C}$, Shahbaz $\mathrm{M}$, Zhengchuan $\mathrm{N}$, Wang J, Liang $\mathrm{B}$, et al. Diagnosis and treatment experience of rectal carcinoid (a report of 312 cases). Int J Surg. 2014; 12: 408-11.

22. Chen WJ, Wu N, Zhou JL, Lin GL, Qiu HZ. Full-thickness excision using transanal endoscopic microsurgery for treatment of rectal neuroendocrine tumors. World J Gastroenterol. 2015; 21: 9142-9.

23. Arezzo A, Passera R, Saito Y, Sakamoto T, Kobayashi N, Sakamoto N, et al. Systematic review and meta-analysis of endoscopic submucosal dissection versus transanal endoscopic microsurgery for large noninvasive rectal lesions. Surg Endosc. 2014; 28: 427-38.

24. Sung HY, Kim SW, Kang WK, Kim SY, Jung CK, Cho YK, et al. Long-term prognosis of an endoscopically treated rectal neuroendocrine tumor: 10-year experience in a single institution. Eur J Gastroenterol Hepatol. 2012; 24: 978-83.

25. Kaneko H, Hirasawa K, Koh R, Kobayashi R, Kokawa A, Tanaka K, et al. Treatment outcomes of endoscopic resection for rectal carcinoid tumors: an analysis of the resectability and long-term results from 46 consecutive cases. Scand J Gastroenterol. 2016; 51: 1489-94.

26. Kim GU, Kim KJ, Hong SM, Yu ES, Yang DH, Jung KW, et al. Clinical outcomes of rectal neuroendocrine tumors $</=10 \mathrm{~mm}$ following endoscopic resection. Endoscopy. 2013; 45: 1018-23.

27. Zhong DD, Shao LM, Cai JT. Endoscopic mucosal resection vs endoscopic submucosal dissection for rectal carcinoid tumours: a systematic review and meta-analysis. Colorectal Dis. 2013; 15: 283-91.

28. Chen T, Yao LQ, Xu MD, Zhang YQ, Chen WF, Shi O, et al. Efficacy and Safety of Endoscopic Submucosal Dissection for Colorectal Carcinoids. Clin Gastroenterol Hepatol. 2016; 14: 575-81.

29. Lee DS, Jeon SW, Park SY, Jung MK, Cho CM, Tak WY, et al. The feasibility of endoscopic submucosal dissection for rectal carcinoid tumors: comparison with endoscopic mucosal resection. Endoscopy. 2010; 42: 647-51. 